\title{
The CSI Effect(s no one?)
}

\author{
David Errickson, Stephanie B. Giles and Graeme Horsman
}

The CSI effect is the notion that individuals have unrealistic expectations of forensic science due to the nature of accessible media such as television programmes. Many argue that the realism of popular franchises (seen within the CSI network of television programmes) influence an individual's perception of what is realistic in terms of forensic evidence recovery and the interpretation and use of forensic evidence to support a criminal investigation. Considering the term 'CSI Effect' was first coined over a decade ago, it could be argued that this phenomenon now extends beyond crime-based television programmes. For example, literature, video games, and the media via news articles, may also play a role in this 'effect'. There is a concern that those involved in courtroom processes carry misplaced preconceptions of any presented forensic science evidence leading to disengagement or misinterpretation of the forensic expert witness testimonies presented in court. Consequently, this could lead to a lack of engagement by jurors and non-forensic professionals with the way real forensic evidence is presented in the courtroom, or worse, cultivate jurors to expect a greater standard of proof of guilt.

The CSI effect is often debated to impact beyond the courtroom in serving a role to educate criminals, where for example, this could extend to how criminals gain entry to a property or to the disposal of a body. However, this link is tenuous with no validating evidence to this effect (Baranowski et al 2018). Likewise, it could be debated as to whether the CSI effect impacts the professional forensic scientist. This could potentially influence the initial recruitment of forensic practitioners, however once employed within the discipline of forensic science, adherence to the national occupational standards and the forensic science regulator (FSR) would quickly diminish the various impacts of such effect. Conversely, the CSI effect may be cited as having had a positive impact on education and research, drawing increased attention to the forensic field of study and the associated discipline areas. Likewise, technological and investigative developments may have been influenced by such media representations. Therefore, the authors would argue that if there is an effect, it is likely confined to non-forensic professionals.

Clearly, the public have the potential to impact forensic science within the courtroom, so openly addressing misconceptions must start at the scene. For example, the actual recovery of evidence, its forensic potential, and the crime scene investigators who advise at the scene; to the format in which evidence is then discussed within the courtroom, which should all be considered throughout the investigation. This should then be managed in court by the expert witness when defining the scope and use of their evidence to dispel any myths. Interestingly, the discussion on the CSI effect encroaches on specific areas and sub-disciplines of forensic science, some more so than others. Therefore, addressing this 'phenomenon' will affect certain expert witnesses within specific disciplines as opposed to others. For example, the impact on the decision-making process has been addressed by numerous authors in forensic anthropology (Nakhaeizadeh et al 2014), yet the discussion within digital forensics or policing is limited.

Perhaps this 'impact' comes down to policy-led investigations versus decision-led investigations. However, it is necessary to state that the forensic science disciplines are facing some of its most severe 
scrutiny to date, noted in the 2019 House of Lord enquiry into the use of forensic evidence in the criminal justice system in England and Wales (House of Lords 2019). Further, with somewhat enforced adherence to ISO standards for forensic processes (see 17020/25), analytical and interpretive techniques should now be validated before use, offering little scope for misinterpretation or misbelief of forensic evidence. With this, and the fact that forensic scientists are actually good at their discipline, the authors ask, is there even a CSI effect? 'Effect' suggests that something has changed based on action, and the literature is yet to quantify and determine after all these years conclusively that CSI has affected anything. According to Google Trends, the interest in the 'CSI effect' has been in decline since 2014. CSI entertainment is now everywhere and perhaps the novelty is no longer a consideration and that the expectation may be less heightened because of it being the 'norm'. This is in conjunction with the more realistic portrayal of forensic evidence in current media bridging the gap between public perception of CSI against actual CSI as programmes actively seek the advice of current forensic professionals. This coupled with the suggestion that only $10 \%$ of cases involving forensic evidence reach a trial in court (Gallop \& Squibb-Williams 2015), there is a limitation to the number of cases the effect can impact on.

Attribution of misunderstanding and the cause of the 'CSI effect' could potentially be credited to miseducation, or the un-education of some individuals. In high profile cases, jurors could be forgiven for their expectation of accurate and novel techniques to be used in finding the truth. However, other processes such as cognitive bias or confirmation bias can greatly affect the mindset of professionals and laypersons alike. These overlap with the termed CSI effect, and in some scenarios have been shown to negatively impact the juror's decision-making process (Nakhaeizadeh et al 2014), but again we ask, is this attributed to the individual's understanding, or is there even a CSI effect?

To summarize, the authors believe that if the CSI effect does exist, the effect is confined only to public perception, bearing no influence to working forensic practitioners. Cole (2013) suggests that the term 'CSI effect' is ill-defined and often used inconsistently. As a result, Cole argues that the term could be an amalgamation of different effects (such as the defendant's effect or the prosecutor's effect). Likewise, no longer are TV shows the driving force in this proclaimed effect, and in fact may involve the wider scope of forensic science and our society. The very fact that it does not just involve the investigative process, possibly there should be a name change that encompasses digital and cyber, policing, and other disciplines, and other aspects of the investigation. Maybe the, 'forensic effect' or 'forensic perception' is much more fitting, or maybe we should stop referring to our misconceived perceptions as an effect at all and more as a misunderstanding of the scientific facts.

References:

Baranowski, A. M., Burkhardt, A., Czernik, E., Hecht, H. 2018. The CSI-education effect: do potential criminals benefit from forensic TV series? International Journal of Law, Crime \& Justice. 52: 86-97.

Cole, S. A. 2013. A surfeit of science: the "CSI effect" and the media appropriation of the public understanding of science. Public Understanding of Science 24 (2): 130-146. 
Gallop, D., Squibb-Williams, K. 2015. Forensic Science in Context. In: Forensic Science and Beyond: Authenticity, Provenance and Assurance: Evidence and Case Studies. Government Office for Science / Annual Report of the Government Chief Scientific Adviser.

House of Lords, 2019, Forensic Science and the Criminal Justice System: A Blueprint for Change. 3rd Report of Session 2017-2019 -

https://publications.parliament.uk/pa/ld201719/Idselect/ldsctech/333/333.pdf

Nakhaeizadeh, S., Dror, I., Morgan, R. 2014. Cognitive bias in forensic anthropology: visual assessment of skeletal remains is susceptible to confirmation bias. Science \& Justice 54: 208-14. 